\title{
Phase Behavior and Formation of O/W Nano-Emulsion in Vegetable Oil/ Mixture of Polyglycerol Polyricinoleate and Polyglycerin Fatty Acid Ester/Water Systems
}

\author{
Satoshi Wakisaka ${ }^{1,2}$, Masami Nakanishi ${ }^{3}$ and Shoichi Gohtani ${ }^{3 *}$ \\ ${ }^{1}$ Department of Food Science, The United Graduate School of Agricultural Sciences, Ehime University (2393 Ikenobe, Miki-cho, Kagawa \\ 761-0795, JAPAN) \\ ${ }^{2}$ Development Department, Glico Nutrition Co., Ltd. (7-16 Kasuga-cho, Takatsuki, Osaka 569-0053, JAPAN) \\ ${ }^{3}$ Department of Applied Biological Science, Faculty of Agriculture, Kagawa University (2393 Ikenobe, Miki-cho, Kagawa 761-0795, JAPAN)
}

\begin{abstract}
It is reported that mixing polyglycerol polyricinoleate (PGPR) and polyglycerol laurilester has a great emulsifying capacity, and consequently fine oil-in-water ( $0 / w)$ emulsions can be formed. However, the role of PGPR is not clear. The objective of this research is to investigate the phase behavior of vegetable oil/ mixture of PGPR and polyglycerol fatty acid ester/water systems, and to clarify the role of PGPR in making a fine emulsion. Phase diagrams were constructed to elucidate the optimal process for preparing fine emulsions. In all the systems examined in this study, the phases, including the liquid crystal phase $\left(\mathrm{L}_{c}\right)$ and sponge phase $\left(L_{3}\right)$, spread widely in the phase diagrams. We examined droplet size of the emulsions prepared from each phase and found that $0 / \mathrm{w}$ nano-emulsions with droplet sizes as small as $50 \mathrm{~nm}$ were formed by emulsifying either from a single $L_{3}$ phase or a two-phase region, $L_{c}+L_{3}$. These results indicate that a sponge phase $L_{3}$ or liquid crystal phase $L c$ or both is necessary to form an $0 / w$ nano-emulsion whose average droplet diameter is less than $\mathbf{5 0} \mathrm{nm}$ for PGPR and polyglycerin fatty acid ester mixtures used as surfactant.
\end{abstract}

Key words: PGPR, nano-emulsion, phase diagram, sponge phase, liquid crystal

\section{INTRODUCTION}

Nano-emulsions are emulsions with droplet sizes typically in the range of $20-200 \mathrm{~nm}$. Due to their small droplet size, they may appear transparent or translucent to the naked eye ${ }^{1}$. Since the very small droplet size causes a substantial reduction in the buoyancy and gravitational forces acting on the droplets, Brownian motion may be sufficient to overcome these effects. As a result, creaming and sedimentation during storage may be reduced or eliminated. The small droplet size also aids in preventing flocculation of the droplets ${ }^{2}$.

The application of nano-emulsion technology in the food, medical and pharmaceutical industries has received great attention from the scientific community. The technology is particularly suited to the fabrication of encapsulating systems for functional compounds because it prevents degradation and improves bioavailability ${ }^{3)}$.

External energy is required to form nano-emulsions since it is a non-equilibrium system. The methods of pre- paring nano-emulsions can be categorized into two types: physical and chemical. Physical methods involve an intensive energy input using a high-shear stirrer or a high-pressure homogenizer. Chemical methods, such as liquid-crystal emulsification ${ }^{4)}$, surfactant phase emulsification ${ }^{5,6)}$ and phase inversion emulsification ${ }^{7-9)}$, use spontaneous phase transitions that are driven by thermodynamic effects. Chemical methods thus allow for the preparation of nanoemulsions at a constant temperature with minimal energy input ${ }^{10)}$. However, the preparation of nano-emulsions from food ingredients such as vegetable oil using low-energy emulsification methods has rarely been reported ${ }^{11-13)}$.

On the other hand, it is reported that a mixture of polyglycerol polyricinoleate(PGPR) and polyglycerol laurilester has a great emulsifying capacity, and consequently, fine oilin-water $(\mathrm{o} / \mathrm{w})$ emulsions can be formed ${ }^{14)}$. PGPR, a nonionic surfactant, is allowed as a food additive in many countries and is a powerful lipophile emulsifier, which can be used to obtain stable water-in-oil (w/o) and water-in-oil-

\footnotetext{
*Correspondence to: Shoichi Gohtani, Department of Applied Biological Science, Faculty of Agriculture, Kagawa University, 2393 Ikenobe, Miki-cho, Kagawa 761-0795, JAPAN

E-mail: gohtani@ag.kagawa-u.ac.jp

Accepted November 19, 2013 (recieved for review August 21, 2013)

Journal of Oleo Science ISSN 1345-8957 print / ISSN 1347-3352 online

http://www.jstage.jst.go.jp/browse/jos/ http://mc.manusriptcentral.com/jjocs
} 


\section{S. Wakisaka, M. Nakanishi and S. Gohtani}

in-water (w/o/w) emulsions ${ }^{15,16)}$. The high emulsifying properties of PGPR are attributed to the excellent water-binding capacity of the long hydrophilic polyglycerol chain. It has been reported that when used at concentrations $>2 \%$, w/o and w/o/w emulsions attain remarkable stability ${ }^{17)}$. In the food industry, PGPR is as effective as lecithin in lowering the viscosity of chocolate to improve its molding properties, with the best effects obtained from PGPR/lecithin mixtures ${ }^{18)}$. However, there have been few reports of PGPR being used to prepare o/w emulsions without the patent ${ }^{14)}$. The role of PGPR in making a fine emulsion for a mixture system with polyglycerol fatty acid ester is also not clear.

The objective of this research is to investigate the phase behavior of vegetable oil/mixture of PGPR and polyglycerol fatty acid ester/water systems, and to clarify the emulsification mechanism of PGPR for the mixture systems.

\section{EXPERIMENTAL PROCEDURES}

\subsection{Materials}

PGPR, (commercial name SY-Glyster CRS-75), decaglycerol monolaurilester (commercial name SY-Glyster ML750), hexaglycerol monolaurilester (commercial name SYGlyster ML-500) and decaglycerol monomyristilester (commercial name SY-Glyster MM-750) were purchased from Sakamoto Yakuhin Kogyo Co. Vegetable oil was purchased from Nisshin Oilio Co. All materials were used without further purification. Purified water was prepared using an E-pure system (Dubuque, USA).

We used a mixture of PGPR with polyglycerol fatty acid ester (ratio 1:1) in this study. The mixtures of PGPR and decaglycerol monolaurilester, PGPR and hexaglycerol monolaurilester, and PGPR and decaglycerol monomyristilester are abbreviated as surfactant DLP, surfactant HLP and surfactant DMP, respectively.

\subsection{Methods}

\subsubsection{Determination of the phase diagram}

Test tubes containing mixtures with the desired compositions were repeatedly shaken using a vortex mixer and then stored at $25^{\circ} \mathrm{C}$. The formation of liquid crystals was confirmed using polarizing plates placed on either side of the test tube. If a uniform liquid crystalline phase was formed, the light passed through the plates due to the birefringence of the liquid crystal. Detailed phases were identified using polarized light microscopy (OLYMPUS, BH-2) and small-angle X-ray scattering (SAXS) techniques.

\subsubsection{Small-angle X-ray scattering}

SAXS measurements were performed on a Nano-Viewer SAXS instrument(Rigaku Co., Tokyo, Japan) equipped with a PILATUS at an applied voltage and filament current of 40 $\mathrm{kV}$ and $30 \mathrm{~mA}$, respectively.

\subsubsection{Preparation of an O/W emulsion}

The emulsifier mixtures previously described, water and vegetable oil were mixed at the desired weight ratios to prepare mixtures before emulsification. Water $(7 \mathrm{~g})$ was then added dropwise to $3 \mathrm{~g}$ of the mixture before emulsification with stirring using a mechanical stirrer at $300 \mathrm{rpm}$ and $25^{\circ} \mathrm{C}$ to prepare an o/w emulsion.

2.2.4 Measurement of the particle-size distribution

Particle-size distribution was determined using a dynamic light scattering device(FPER-1000; Otsuka Electronics, Osaka, Japan).

\section{RESULTS AND DISCUSSION}

\subsection{Phase behavior}

The phase diagram for the vegetable oil/surfactant DLP/ water system (system A) at $25^{\circ} \mathrm{C}$ is shown in Fig. 1. Figure 2 shows the polarized microphotographs, and SAXS patterns of mixtures of compositions (a) and (b) described in Fig. 1.

The sponge phase $\left(\mathrm{L}_{3}\right)$ is often stated to be flow birefringent ${ }^{19)}$, and it is reported that the SAXS pattern obtained from $\mathrm{L}_{3}$ indicates a broad peak ${ }^{20)}$. The sample represented by composition(a) in Fig. 1 was a visually transparent isotropic phase and did not show birefringence under polar-

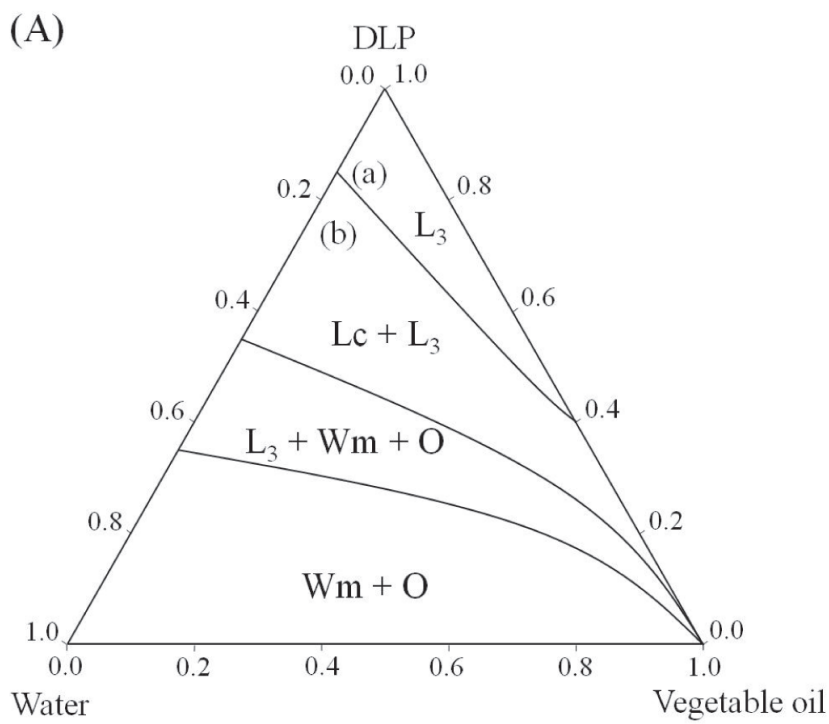

Fig. 1 Phase diagram of system A (vegetable oil/surfactant DLP/water system) at $25^{\circ} \mathrm{C} . \mathrm{L}_{3}, \mathrm{Lc}, \mathrm{Wm}$ and $\mathrm{O}$ indicate a sponge phase, a liquid crystal phase, a micellar phase and an oil phase, respectively. $\mathrm{L}_{\mathrm{c}}+\mathrm{L}_{3}$ indicates a two-phase equilibrium consisting of a liquid crystal phase and a sponge phase. $\mathrm{Wm}+\mathrm{O}$ and $\mathrm{L}_{3}+\mathrm{Wm}+\mathrm{O}$ indicate twoand three-phase equilibrium of $\mathrm{Wm}$ and $\mathrm{L}_{3}+$ Wm with an expelled oil phase, respectively. 
(a)
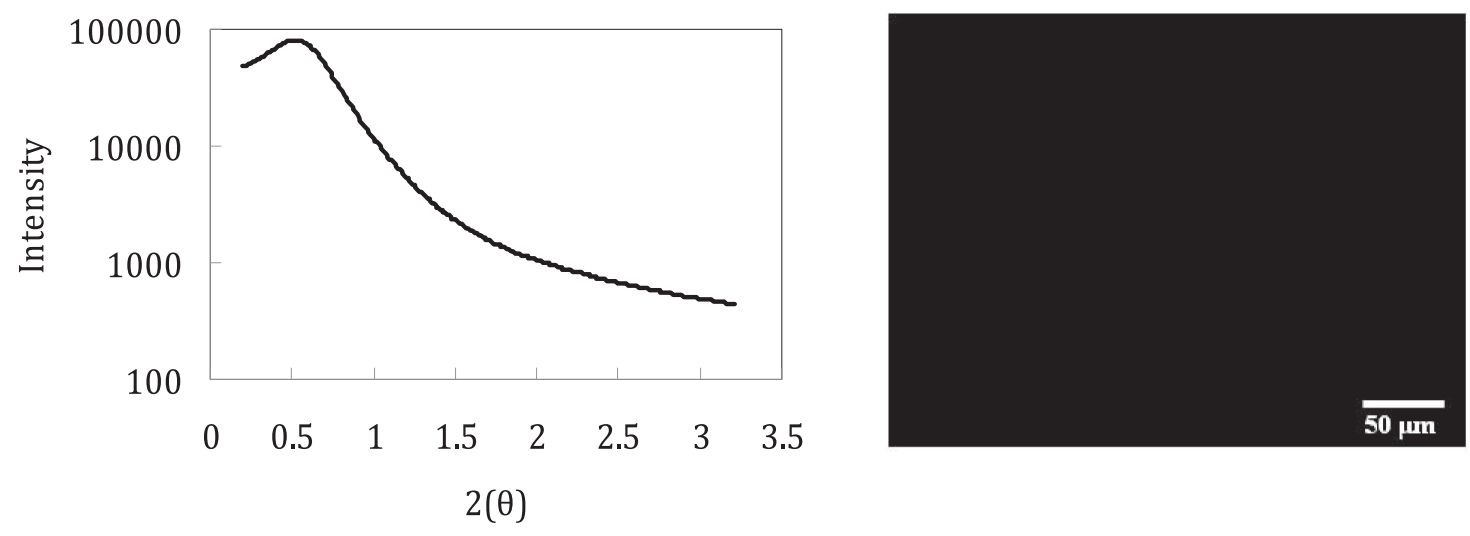

(b)
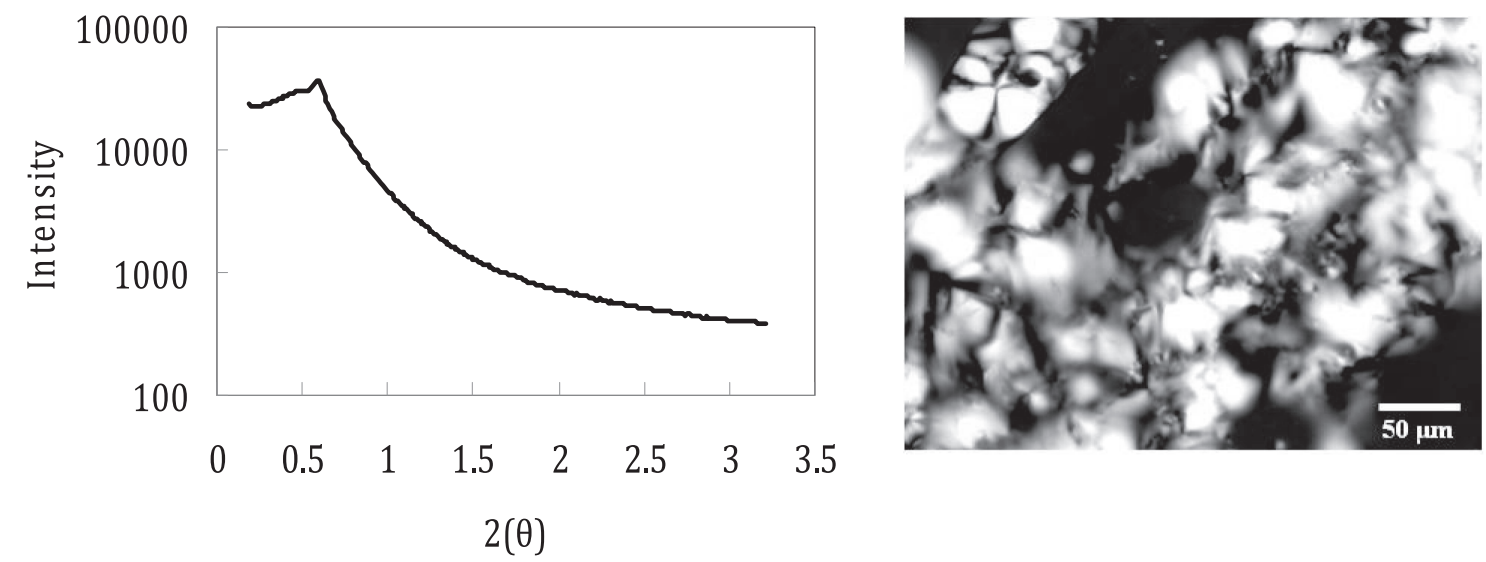

Fig. 2 Polarized microscopic images and SAXS patterns of samples consisting of $10.0 \mathrm{wt} \%, 80.0 \mathrm{wt} \%$, and $10.0 \mathrm{wt} \%$ (a); $10.0 \mathrm{wt} \%, 75.0 \mathrm{wt} \%$, and $15.0 \mathrm{wt} \%$ (b) of vegetable oil, surfactant DLP, and water, respectively. Compositions (a) and (b) are indicated in Fig. 1 using the corresponding letters in parentheses.

ization microscopy (Fig. 2 (a)) or between crossed polarizes in a static state (Fig. 3(A)). However, this sample showed flow birefringence between crossed polarizes in a flow state (Fig. 3(B)) . Consequently, this phase was identified as $\mathrm{L}_{3}$. For system A (vegetable oil/surfactant DLP/water), $\mathrm{L}_{3}$ could be seen at surfactant DLP and water content above $40 \mathrm{wt} \%$ and below $15 \mathrm{wt} \%$, respectively.

From the micrograph shown in Fig. 2(b), the samples represented by composition(b) in Fig. 1 were determined to form a liquid crystalline $\left(\mathrm{L}_{\mathrm{c}}\right)$ phase. In addition, when these samples flowed between crossed polarizes, the samples showed birefringence more intensively. Consequently, we determined that these phases are a two-phase region coexisting with $\mathrm{L}_{c}$ and $\mathrm{L}_{3}$. The scattering peaks for sample(b) in Fig.1 were broad. These scattering peaks indicate the presence of a type of liquid crystal. We presume that the type of liquid crystal is not cubic liquid crystal, which does not show birefringence under polarization microscopy $^{21)}$. However, the type of liquid crystal, for example, lamellar liquid crystal and hexagonal liquid
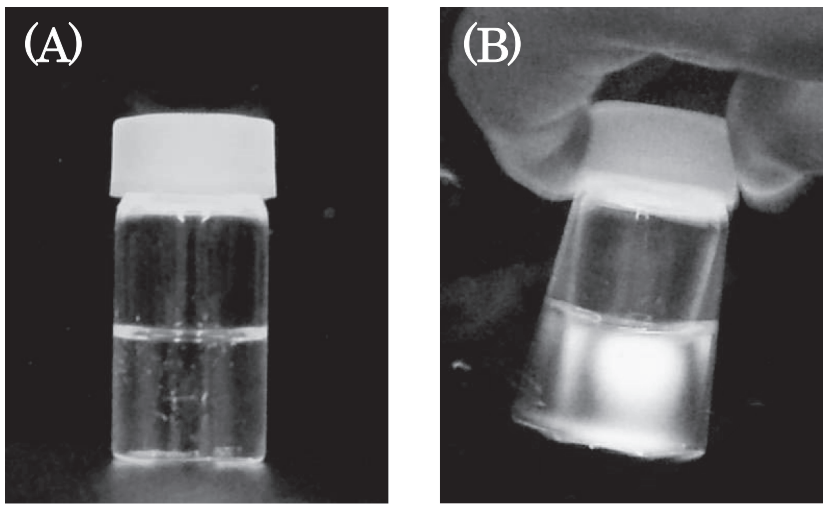

Fig. 3 Photographs of sample represented by composition (a) in Fig. 1 (vegetable oil: $10 \mathrm{wt} \%$, surfactant DLP: 80 wt $\%$, water: 10 wt $\%$ ) between crossed polarizes, in static state (A) and in flow state (B). 


\section{S. Wakisaka, M. Nakanishi and S. Gohtani}

crystal, could not be determined since the SAXS profile for sample (b) showed one broad peak and one narrow peak. At least two narrow peaks are necessary to determine the type of liquid crystal(Fig. 2b). Even though we could not confidently identify the type of liquid crystal in these phases, for system A, a region with two coexisting phases, $\mathrm{L}_{\mathrm{c}}$ and $\mathrm{L}_{3}$, appeared when the content of surfactant DLP and water was below 85 wt \% and below 45 wt\%, respectively. When the content of surfactant DLP and water was below 55 wt $\%$ and below 65 wt $\%$, respectively, a threephase region with $\mathrm{L}_{3}$, micelle solution and an oil phase $\left(\mathrm{L}_{3}\right.$ $+\mathrm{Wm}+\mathrm{O}$ ) could be seen. At surfactant DLP content less than 35 wt \%, a two-phase region $(\mathrm{Wm}+\mathrm{O})$ was confirmed.

The phase diagram for the vegetable oil/surfactant HLP/ water system (system B) at $25^{\circ} \mathrm{C}$ is shown in Fig. 4. Figure 5 shows polarized microscopic images and SAXS patterns of the mixtures (a), (b) and (c) shown in Fig. 4. From the micrograph shown in Fig. 5(a),(b) and (c), the samples represented by composition(a), (b) and (c) in Fig. 4 were determined to form an $\mathrm{L}_{\mathrm{c}}$ phase. The SAXS pattern obtained from samples (a) and (c) showed 3 peaks. We considered the first peak to be $\mathrm{L}_{3}$, because these peaks were broad. The scattering peak ratio of the secondary peak to the third peak for both (a) and (c) shown in Fig. 5 were

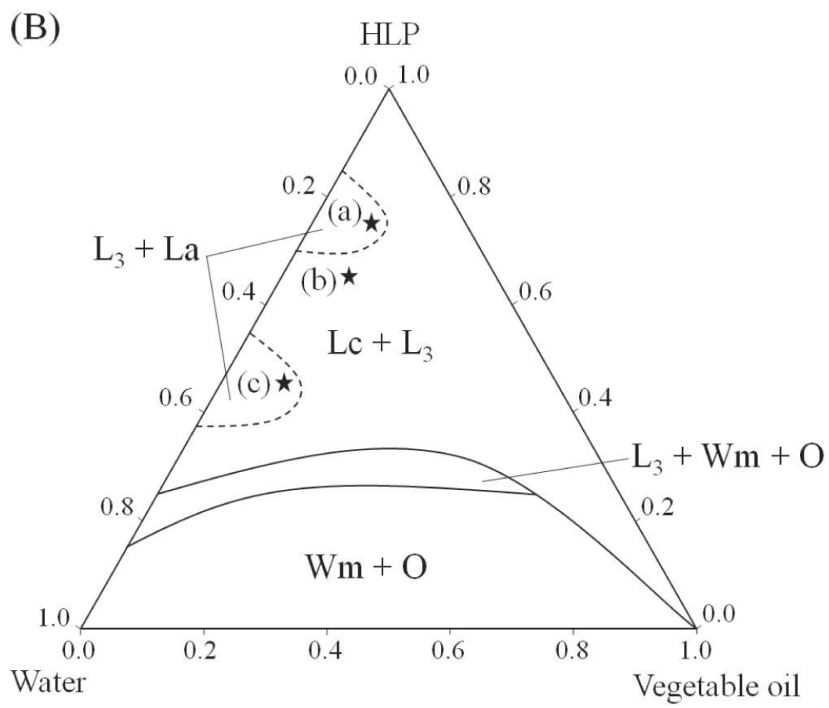

Fig. 4 Phase diagram of system B (vegetable oil/surfactant $\mathrm{HLP} /$ water system) at $25^{\circ} \mathrm{C} . \mathrm{L}_{3}, \mathrm{~L}_{\mathrm{c}}$, La, $\mathrm{Wm}$ and $\mathrm{O}$ indicate a sponge phase, a liquid crystal phase, a lamellar phase, a micellar phase and an oil phase, respectively. $\mathrm{L}_{\mathrm{c}}+\mathrm{L}_{3}$ and $\mathrm{L}_{3}+$ La indicate a two-phase equilibrium consisting of a liquid crystal phase and a sponge phase, a sponge phase and a lamellar phase, respectively. $\mathrm{Wm}+\mathrm{O}$ and $\mathrm{L}_{3}+\mathrm{Wm}+\mathrm{O}$ indicate two- and three-phase equilibrium of $\mathrm{Wm}$ and $\mathrm{L}_{3}+\mathrm{Wm}$ with an expelled oil phase, respectively.
1:1/2, and the micrograph in Fig. 5(a) and (c) shows a typical extinction-cross texture for a lamellar phase $(\mathrm{La})^{19)}$. Thus, it is considered that a lamellar liquid crystal was formed in these regions. Consequently, (a) and (c) shown in Fig. 4 were identified as $\mathrm{L}_{3}+\mathrm{La}$. On the other hand, the SAXS pattern obtained from sample (b) shown in Fig. 5 did not correspond to any liquid crystalline structure, for example, lamellar liquid crystal or hexagonal liquid crystal. In addition, the flow birefringence between crossed polarizes was also observed for sample(b), which overlaps with the birefringence of liquid crystal. We think that this phase is $\mathrm{L}_{\mathrm{c}}+\mathrm{L}_{3}$.

The inter-bilayer spacing $d=\lambda / 2 \sin \theta$ of the lamella structure of sample(a) in Fig. 4 was $6.53 \mathrm{~nm}$ and that of sample(c) was $17.3 \mathrm{~nm}$. The composition of sample(a) was 1.0:7.5:1.5 (oil:surfactant:water) and that of sample (c) was 1.0:5.5:4.0 (oil:surfactant:water). It is clear that the interbilayer spacing for lamella structure increased with an increase in the content of water. It is considered that the distance between the hydrophilic plates for the lamella structure increased due to the increasing number of water molecules.

For system $\mathrm{B}, \mathrm{L}_{\mathrm{c}}+\mathrm{L}_{3}$ spread toward the low surfactant HLP content region. Moreover, there were two regions with La in $\mathrm{L}_{\mathrm{c}}+\mathrm{L}_{3}$ (dotted line in Fig. 4). At a vegetable oil content below $15 \mathrm{wt} \%$, one region of $\mathrm{L}_{3}+\mathrm{La}$ was observed when the content of surfactant HLP and water was approximately 70-85 wt \% and 15-30 wt\%, respectively, and the other region was observed when the content of surfactant HLP and water was approximately 40-55 wt\% and 45-60 wt \%, respectively. At a vegetable oil content below 60 wt $\%$, three phases with $\mathrm{L}_{3}+\mathrm{Wm}+\mathrm{O}$ was observed when the content of surfactant HLP and water was approximately 25-35 wt \% and 15-85 wt\%, respectively. When surfactant HLP content was below about $15-25 \mathrm{wt} \%, \mathrm{Wm}+\mathrm{O}$ was confirmed.

For system $B$, the region of $\mathrm{L}_{c}+\mathrm{L}_{3}$ is much wider than that of system A on the phase diagram. It is considered that the hexaglycerol monolaurilester (HGML) in system B tended to orient rather than the decaglycerol monolaurilester(DGML) in system A because the hydrophilic group of HGML was smaller than that of DGML.

As shown in Fig. 6, the phase diagram for vegetable oil/ surfactant DMP/water system (system C) was similar to that for system A (Fig. 1). All phases were determined by polarized microscopic images, observation of test tubes containing samples between polarizing plates and SAXS measurement, the same as the methods described above. $\mathrm{L}_{3}$ could be seen at surfactant DMP and water content above about $40 \mathrm{wt} \%$ and below about $10 \mathrm{wt} \%$, respectively. A region with two coexisting phases, $\mathrm{L}_{\mathrm{c}}$ and $\mathrm{L}_{3}$, appeared when the content of surfactant DMP and water were $90 \mathrm{wt} \%$ and below 60 wt \%, respectively. In this system, the type of liquid crystal for $\mathrm{L}_{\mathrm{c}}$ could not be identified, similar to the 
(a)
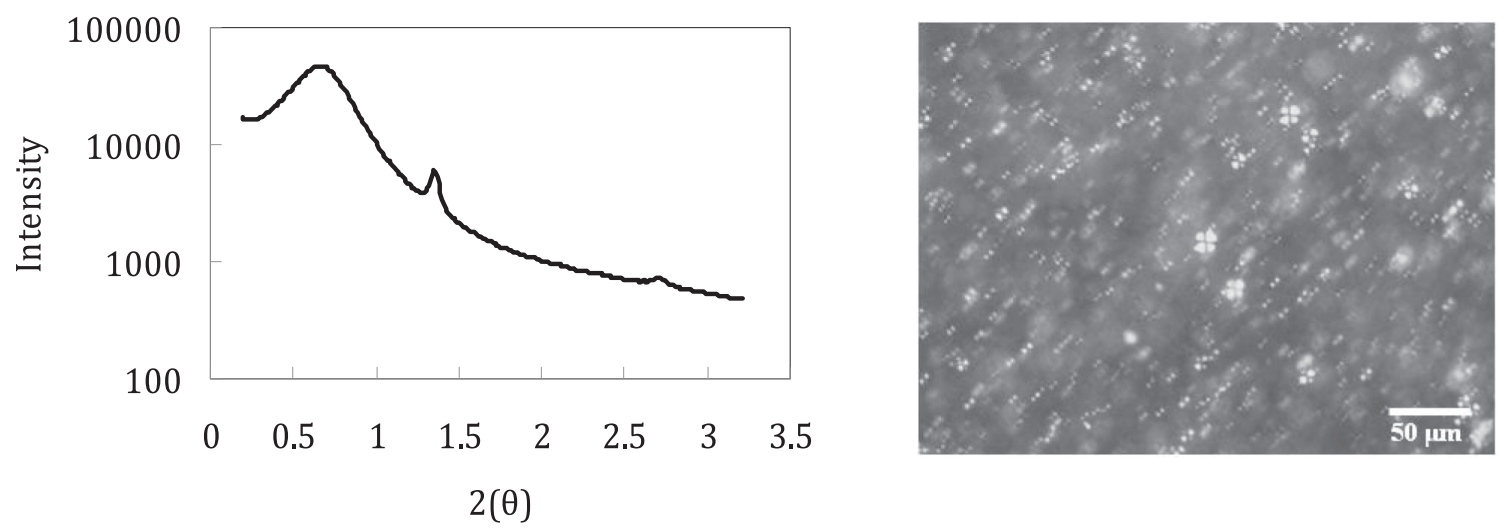

(b)
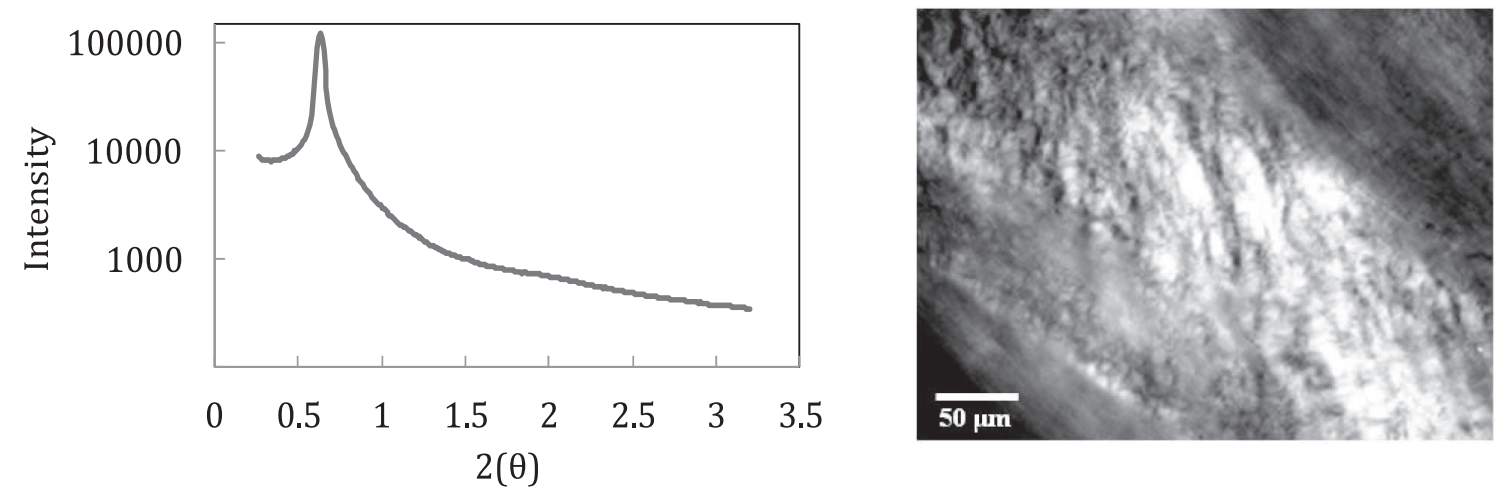

(c)
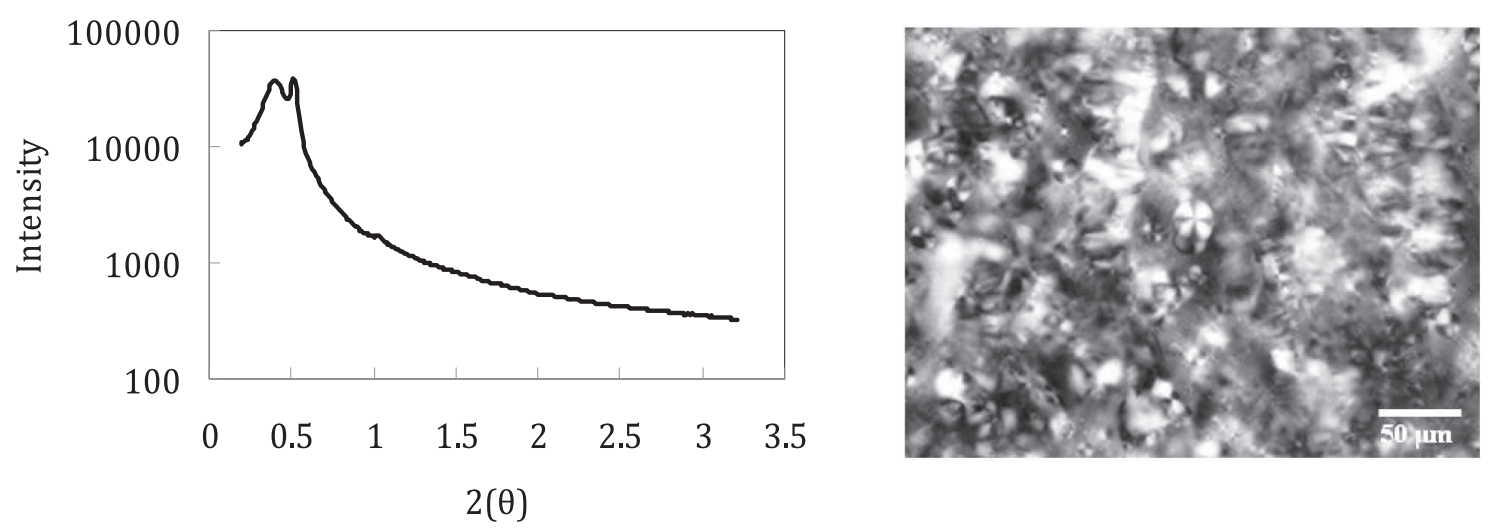

Fig. 5 Polarized microscopic images and SAXS patterns of samples consisting of $10.0 \mathrm{wt} \%, 75.0 \mathrm{wt} \%$, and $15.0 \mathrm{wt} \%$ (a); $10.0 \mathrm{wt} \%, 65.0 \mathrm{wt} \%$, and $25.0 \mathrm{wt} \%$ (b); $10.0 \mathrm{wt} \%, 50.0 \mathrm{wt} \%$, and $40.0 \mathrm{wt} \%$ (c) of vegetable oil, surfactant HLP, and water, respectively. Compositions (a), (b), and (c) are indicated in Fig. 4 using the corresponding letters in parentheses.

case as described above for system A. When the content of surfactant DMP and water was below $45 \mathrm{wt} \%$ and below 60 wt $\%$, respectively, a three-phase region with $\mathrm{L}_{3}+\mathrm{Wm}+\mathrm{O}$ could be seen. At surfactant DMP content of less than 40 $\mathrm{wt} \%, \mathrm{Wm}+\mathrm{O}$ was formed.
For system $\mathrm{C}$, the region of $\mathrm{L}_{\mathrm{c}}+\mathrm{L}_{3}$ is slightly wider than that of system A on the phase diagram. We expect that decaglycerol monomyristilester (DGMM) in system $\mathrm{C}$ is slightly more hydrophobic than DGML in system A because the fatty acid chain of $\operatorname{DGMM}(\mathrm{C} 14)$ is longer than that of 


\section{S. Wakisaka, M. Nakanishi and S. Gohtani}

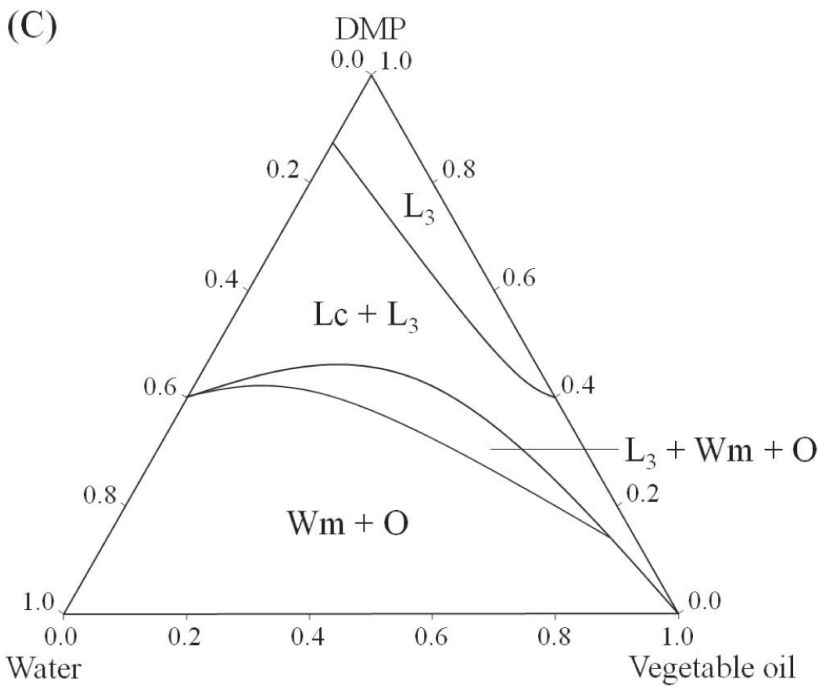

Fig. 6 Phase diagram of system C (vegetable oil/surfactant DMP/water system) at $25^{\circ} \mathrm{C} . \mathrm{L}_{3}, \mathrm{Lc}, \mathrm{Wm}$ and $\mathrm{O}$ indicate a sponge phase, a liquid crystal phase, a micellar phase and an oil phase, respectively. $\mathrm{L}_{\mathrm{c}}+\mathrm{L}_{3}$ indicates a two-phase equilibrium consisting of a liquid crystal phase and a sponge phase. $\mathrm{Wm}+\mathrm{O}$ and $\mathrm{L}_{3}+\mathrm{Wm}+\mathrm{O}$ indicate twoand three-phase equilibrium of $\mathrm{Wm}$ and $\mathrm{L}_{3}+$ Wm with an expelled oil phase, respectively.

DGML (C12) .

\subsection{Preparation of nano-emulsion}

An o/w emulsion was prepared as described in the experimental section (2.2.3). The average droplet diameter of the emulsion depended highly on the phase type, suggesting that the physicochemical properties of the phase critically affected the properties of the resulting emulsion.

Table 1 shows the phase type and weight composition of the samples before emulsification and the average droplet diameter of the $\mathrm{o} / \mathrm{w}$ emulsions prepared from the samples as described in the experimental section(2.2.3). The UM in Table 1 means the samples could not be used to determine the droplet size of the emulsion because the w/o emulsion was contained in the sample or the oil spread on the sample.

Figure 7 shows a photograph of the o/w emulsions prepared from samples I to VIII indicated in Table 1.

In system $\mathrm{A}$, containing the 1.0 ratio of oil (Table 1 system A-a) and a water ratio of 0.5-3.5, the phase type of the mixtures before emulsification was $\mathrm{L}_{3}$ or $\mathrm{L}_{\mathrm{c}}+\mathrm{L}_{3}$, the average droplet diameter of the prepared o/w emulsions was about $30 \mathrm{~nm}$, and the emulsions were bluish and translucent (Fig. 7 System A I-VII). When the phase type of the mixture before emulsification changed to $\mathrm{L}_{3}+\mathrm{Wm}+\mathrm{O}$ or $\mathrm{Wm}+\mathrm{O}$, the droplet diameter of the prepared emulsions was more than about $200 \mathrm{~nm}$, and the emulsions were milky white (Fig. 7 System A VIII). The droplet diameter and appearance changed remarkably even though the content of the samples was not so different. For the 4.0 ratio of oil (Table 1 system A-b) and a water ratio of 0.5 1.5, the average diameter was $100 \mathrm{~nm}$ to $130 \mathrm{~nm}$ even in high oil content and the phase types before emulsification were also $\mathrm{L}_{3}$ or $\mathrm{L}_{\mathrm{c}}+\mathrm{L}_{3}$. On the other hand, good o/w emulsion could not be prepared from the region of $\mathrm{L}_{3}+\mathrm{Wm}+\mathrm{O}$ in system A-b.

In system B-a, containing the 1.0 ratio of oil and a water ratio of $0.5-6.0$, the phase type of the mixtures before emulsification was $\mathrm{L}_{\mathrm{c}}+\mathrm{L}_{3}$ or $\mathrm{L}_{3}+\mathrm{La}$, the average droplet diameter of the prepared o/w emulsions was less than 30 $\mathrm{nm}$, and most of the emulsions were transparent(Fig. 7 System B). The average droplet diameter of the o/w emulsions prepared from the $\mathrm{L}_{3}+\mathrm{Wm}+\mathrm{O}$ and $\mathrm{Wm}+\mathrm{O}$ regions was $46.1 \mathrm{~nm}$ and $892.7 \mathrm{~nm}$, respectively. It was considered that $\mathrm{L}_{3}+\mathrm{Wm}+\mathrm{O}$ in system B-a was the border between $\mathrm{L}_{c}$ $+\mathrm{L}_{3}$ and $\mathrm{Wm}+\mathrm{O}$, and thus the average droplet diameter of the o/w emulsions prepared from this sample was smaller than $100 \mathrm{~nm}$. For the 4.0 ratio of oil (Table 1 system B-b) and a water ratio of $0.5-2.5, \mathrm{o} / \mathrm{w}$ nano-emulsion with droplet sizes as low as $100 \mathrm{~nm}$ were formed even in high oil content and the phase type before emulsification was $\mathrm{L}_{c}+$ $\mathrm{L}_{3}$. When the phase type changed to $\mathrm{L}_{3}+\mathrm{Wm}+\mathrm{O}$ or $\mathrm{Wm}+$ $\mathrm{O}$, the droplet diameter of prepared emulsion was more than $250 \mathrm{~nm}$. For system B, the o/w nano-emulsion could be obtained from a wider range than system $\mathrm{A}$.

In system $\mathrm{C}$, containing the 1.0 ratio of oil (Table 1 system C-a) and a water ratio of $0.5-4.5$, the average droplet diameter of the prepared o/w emulsions was 35-45 $\mathrm{nm}$, the phase type of the mixtures before emulsification was $\mathrm{L}_{3}$ or $\mathrm{L}_{\mathrm{c}}+\mathrm{L}_{3}$, and the prepared emulsion was bluish milky white (Fig. 7 System C). For the 4.0 ratio of oil (Table 1 system C-b), even though the phase type before emulsification was $\mathrm{L}_{3}$ or $\mathrm{L}_{\mathrm{c}}+\mathrm{L}_{3}$, a fine emulsion was not prepared in some cases, i.e., the oil:surfactant:water ratio was 4.0:5.5:0.5 or 4.0:5.0:1.0. On the other hand, when the $\mathrm{o} / \mathrm{w}$ nano-emulsion was prepared, the oil:surfactant:water ratio was 1.0:7.5:1.5. We presume that the oil was a continuous phase in the former case and the water was a continuous phase in the latter case.

The results in this paper indicate that a sponge phase $\mathrm{L}_{3}$ or a liquid crystal phase $\mathrm{L}_{\mathrm{c}}$ or both is necessary to form an $\mathrm{o} / \mathrm{w}$ nano-emulsion whose average droplet diameter is less than $50 \mathrm{~nm}$ for PGPR and polyglycerin fatty acid ester mixtures used as surfactant.

Miyanoshita et $a l .{ }^{21)}$ reported that nano-scale droplets about $100 \mathrm{~nm}$ were obtained to cross a lamellar phase for a vegetable oil/decaglycerol monolaurilester(DGML)/40 wt\% sucrose solution system and a sponge phase for a vegetable oil/polyoxyethylene sorbitan monooleate/40 wt\% sucrose solution system along the emulsification path. These results are similar to our observation in the present study. 
Table 1 Phase type and weight composition of the samples before emulsification in each system and the average droplet diameter of the o/w emulsions prepared from the samples before emulsification.

\begin{tabular}{|c|c|c|c|c|c|c|c|}
\hline \multirow{2}{*}{\multicolumn{2}{|c|}{ System of diagram }} & \multicolumn{3}{|c|}{ Weight ratio } & \multirow{2}{*}{ Phase type } & \multirow{2}{*}{$\begin{array}{l}\text { Average droplet } \\
\text { diameter }(\mathrm{nm})\end{array}$} & \multirow{2}{*}{$\begin{array}{l}\text { Sample } \\
\text { number }\end{array}$} \\
\hline & & Oil & Surfactant & Water & & & \\
\hline \multirow{16}{*}{ system A } & \multirow{10}{*}{$\mathrm{a}$} & 1.0 & 8.5 & 0.5 & $\mathrm{~L}_{3}$ & 22.6 & $\mathrm{I}$ \\
\hline & & 1.0 & 8.0 & 1.0 & $\mathrm{~L}_{3}$ & 25.7 & II \\
\hline & & 1.0 & 7.5 & 1.5 & $\mathrm{Lc}+\mathrm{L}_{3}$ & 25.8 & III \\
\hline & & 1.0 & 7.0 & 2.0 & $\mathrm{Lc}+\mathrm{L}_{3}$ & 28.1 & IV \\
\hline & & 1.0 & 6.5 & 2.5 & $\mathrm{Lc}+\mathrm{L}_{3}$ & 27.0 & $\mathrm{~V}$ \\
\hline & & 1.0 & 6.0 & 3.0 & $\mathrm{Lc}+\mathrm{L}_{3}$ & 31.0 & $\mathrm{VI}$ \\
\hline & & 1.0 & 5.5 & 3.5 & $\mathrm{Lc}+\mathrm{L}_{3}$ & 29.9 & VII \\
\hline & & 1.0 & 5.0 & 4.0 & $\mathrm{~L}_{3}+\mathrm{Wm}+\mathrm{O}$ & 198.6 & VIII \\
\hline & & 1.0 & 4.5 & 4.5 & $\mathrm{~L}_{3}+\mathrm{Wm}+\mathrm{O}$ & 316.8 & \\
\hline & & 1.0 & 3.0 & 6.0 & $\mathrm{Wm}+\mathrm{O}$ & 396.1 & \\
\hline & \multirow{6}{*}{$\mathrm{b}$} & 4.0 & 5.5 & 0.5 & $\mathrm{~L}_{3}$ & 102.3 & \\
\hline & & 4.0 & 5.0 & 1.0 & $\mathrm{Lc}+\mathrm{L}_{3}$ & 114.4 & \\
\hline & & 4.0 & 4.5 & 1.5 & $\mathrm{Lc}+\mathrm{L}_{3}$ & 132.5 & \\
\hline & & 4.0 & 4.0 & 2.0 & $\mathrm{~L}_{3}+\mathrm{Wm}+\mathrm{O}$ & $\mathrm{UM}^{*}$ & \\
\hline & & 4.0 & 3.5 & 2.5 & $\mathrm{~L}_{3}+\mathrm{Wm}+\mathrm{O}$ & $\mathrm{UM}^{*}$ & \\
\hline & & 4.0 & 3.0 & 3.0 & $\mathrm{~L}_{3}+\mathrm{Wm}+\mathrm{O}$ & UM* & \\
\hline \multirow{22}{*}{ system B } & \multirow{14}{*}{$\mathrm{a}$} & 1.0 & 8.5 & 0.5 & $\mathrm{Lc}+\mathrm{L}_{3}$ & 32.2 & I \\
\hline & & 1.0 & 8.0 & 1.0 & $\mathrm{Lc}+\mathrm{L}_{3}$ & 28.9 & II \\
\hline & & 1.0 & 7.5 & 1.5 & $\mathrm{~L}_{3}+\mathrm{La}$ & 28.0 & III \\
\hline & & 1.0 & 7.0 & 2.0 & $\mathrm{~L}_{3}+\mathrm{La}$ & 17.8 & IV \\
\hline & & 1.0 & 6.5 & 2.5 & $\mathrm{Lc}+\mathrm{L}_{3}$ & 17.7 & $\mathrm{~V}$ \\
\hline & & 1.0 & 6.0 & 3.0 & $\mathrm{Lc}+\mathrm{L}_{3}$ & 22.8 & VI \\
\hline & & 1.0 & 5.5 & 3.5 & $\mathrm{Lc}+\mathrm{L}_{3}$ & 20.1 & VII \\
\hline & & 1.0 & 5.0 & 4.0 & $\mathrm{Lc}+\mathrm{L}_{3}$ & 22.9 & VIII \\
\hline & & 1.0 & 4.5 & 4.5 & $\mathrm{~L}_{3}+\mathrm{La}$ & 29.3 & \\
\hline & & 1.0 & 4.0 & 5.0 & $\mathrm{~L}_{3}+\mathrm{La}$ & 27.4 & \\
\hline & & 1.0 & 3.5 & 5.5 & $\mathrm{Lc}+\mathrm{L}_{3}$ & 27.9 & \\
\hline & & 1.0 & 3.0 & 6.0 & $\mathrm{Lc}+\mathrm{L}_{3}$ & 29.9 & \\
\hline & & 1.0 & 2.5 & 6.5 & $\mathrm{~L}_{3}+\mathrm{Wm}+\mathrm{O}$ & 46.1 & \\
\hline & & 1.0 & 2.0 & 7.0 & $\mathrm{Wm}+\mathrm{O}$ & 892.7 & \\
\hline & \multirow{8}{*}{$\mathrm{b}$} & 4.0 & 5.5 & 0.5 & $\mathrm{Lc}+\mathrm{L}_{3}$ & 50.8 & \\
\hline & & 4.0 & 5.0 & 1.0 & $\mathrm{Lc}+\mathrm{L}_{3}$ & 61.3 & \\
\hline & & 4.0 & 4.5 & 1.5 & $\mathrm{Lc}+\mathrm{L}_{3}$ & 68.3 & \\
\hline & & 4.0 & 4.0 & 2.0 & $\mathrm{Lc}+\mathrm{L}_{3}$ & 78.5 & \\
\hline & & 4.0 & 3.5 & 2.5 & $\mathrm{Lc}+\mathrm{L}_{3}$ & 100.5 & \\
\hline & & 4.0 & 3.0 & 3.0 & $\mathrm{~L}_{3}+\mathrm{Wm}+\mathrm{O}$ & 257.9 & \\
\hline & & 4.0 & 2.5 & 3.5 & $\mathrm{Wm}+\mathrm{O}$ & 622.6 & \\
\hline & & 4.0 & 2.0 & 4.0 & $\mathrm{Wm}+\mathrm{O}$ & 837.3 & \\
\hline \multirow{14}{*}{ system C } & \multirow{10}{*}{$\mathrm{a}$} & 1.0 & 8.5 & 0.5 & $\mathrm{~L}_{3}$ & 37.2 & I \\
\hline & & 1.0 & 8.0 & 1.0 & $\mathrm{~L}_{3}$ & 40.5 & II \\
\hline & & 1.0 & 7.5 & 1.5 & $\mathrm{Lc}+\mathrm{L}_{3}$ & 38.7 & III \\
\hline & & 1.0 & 7.0 & 2.0 & $\mathrm{Lc}+\mathrm{L}_{3}$ & 35.9 & IV \\
\hline & & 1.0 & 6.5 & 2.5 & $\mathrm{Lc}+\mathrm{L}_{3}$ & 44.1 & $\mathrm{~V}$ \\
\hline & & 1.0 & 6.0 & 3.0 & $\mathrm{Lc}+\mathrm{L}_{3}$ & 39.4 & $\mathrm{VI}$ \\
\hline & & 1.0 & 5.5 & 3.5 & $\mathrm{Lc}+\mathrm{L}_{3}$ & 40.6 & VII \\
\hline & & 1.0 & 5.0 & 4.0 & $\mathrm{Lc}+\mathrm{L}_{3}$ & 37.3 & VIII \\
\hline & & 1.0 & 4.5 & 4.5 & $\mathrm{Lc}+\mathrm{L}_{3}$ & 41.7 & \\
\hline & & 1.0 & 4.0 & 5.0 & $\mathrm{Wm}+\mathrm{O}$ & 1244.6 & \\
\hline & \multirow{4}{*}{ b } & 4.0 & 5.5 & 0.5 & $\mathrm{~L}_{3}$ & $\mathrm{UM}^{*}$ & \\
\hline & & 4.0 & 5.0 & 1.0 & $\mathrm{Lc}+\mathrm{L}_{3}$ & $\mathrm{UM}^{*}$ & \\
\hline & & 4.0 & 4.5 & 1.5 & $\mathrm{Lc}+\mathrm{L}_{3}$ & 126.0 & \\
\hline & & 4.0 & 4.0 & 2.0 & $\mathrm{~L}_{3}+\mathrm{Wm}+\mathrm{O}$ & $\mathrm{UM}^{*}$ & \\
\hline
\end{tabular}

* UM : unmeasurable level 

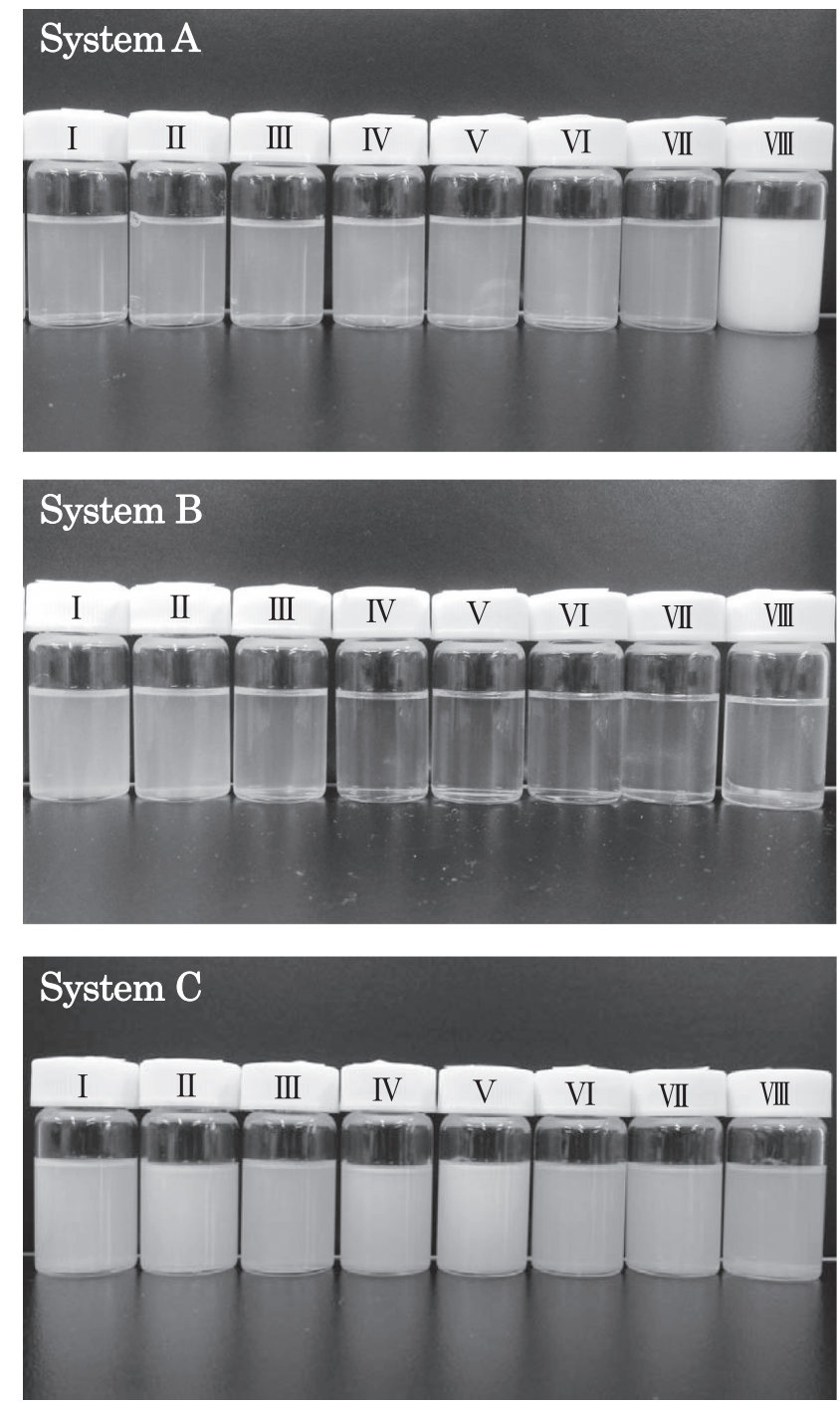

Fig. 7 Photographs of the o/w emulsions prepared using the method described in 2.2.3. The sample number (I-VIII) refers to the number noted in Table 1.

On the other hand, the droplet size of emulsions prepared from the system with PGPR in the present study was almost half that compared with those for the system with single DGML ${ }^{21)}$. This is considered to be because a part of the lamellar structure changed into a sponge structure by mixing PGPR with DGML, and that structure change is advantageous for the formation of an o/w nano-emulsion.

\section{CONCLUSION}

Phase diagrams of vegetable oil/mixture of PGPR and polyglycerin fatty acid ester/water systems were constructed to clarify the mechanism of o/w fine emulsion formation with PGPR. In all the systems examined in this study, the phase, including the liquid crystal phase $\left(\mathrm{L}_{\mathrm{c}}\right)$ and sponge phase $\left(\mathrm{L}_{3}\right)$, spread widely in the phase diagrams. The droplet size of the emulsions prepared from each phase was examined and it was found that an o/w nano-emulsion with droplet sizes as small as $50 \mathrm{~nm}$ were formed by emulsifying either from a single $\mathrm{L}_{3}$ phase or a two-phase region, $\mathrm{L}_{\mathrm{c}}+\mathrm{L}_{3}$. These results indicate that a sponge phase $\mathrm{L}_{3}$ or a liquid crystal phase $\mathrm{L}_{\mathrm{c}}$ or both is necessary to form an o/w nano-emulsion whose average droplet diameter is less than $50 \mathrm{~nm}$ for PGPR and polyglycerin fatty acid ester mixtures used as surfactant.

\section{ACKNOWLEDGMENT}

This work was financially supported by a Grant-in-Aid for Scientific Research (C) from the Ministry of Education, Culture, Sports, Science and Technology of Japan (27500930).

\section{References}

1) Solans, C.; Izquierdo, P.; Nolla J.; Azemar N.; GarciaCelma M. J. Nano-emulsions. Current Opinion in Colloid \& Interface Science 10, 102-110 (2005).

2) Tadros, T.; Izquierdo, P.; Esquena, J.; Solans, C. Formation and stability of nano-emulsions. Adv. Colloid Interface Sci. 108-109, 303-318(2004).

3) Silva, H. D.; Cerqueira, M. A.; Vicente, A. A. Nanoemulsion for food applications: Development and characterization. Food Bioprocess Technol. 5, 854-867 (2012).

4) Suzuki, T.; Takei, H.; Yamazaki, S. Formation of fine three-phase emulsions by the liquid crystal emulsification method with arginine $\beta$-branched monoalkyl phosphate. J. Colloid Interface Sci. 129, 491-500 (1989).

5) Sagitani, H.; Hirai, Y.; Nabeta, K.; Nagai, M. Effect of type of polyols on surfactant phase emulsification. $J$. Jpn. Oil Chem. Soc. 35, 102-107(1986).

6) Sagitani, H. Formation of $\mathrm{O} / \mathrm{W}$ emulsion by surfactant phase emulsification and the solution behavior of nonionic surfactant system in the emulsification process. J. Dispersion Sci. Tech. 9, 115-129(1988).

7) Sajjadi, S. Nanoemulsion formation by phase inversion emulsification: On the nature of inversion. Langmuir 22, 5597-5603 (2006).

8) Sole, I.; Maestro, A.; Gonzales, C.; Solans, C.; Gutierrez, J. M. Optimization of nano-emulsion preparation by low-energy methods in an ionic surfactant system. Langmuir 22, 8326-8332(2006).

9) Pey, C. M.; Maestro, A.; Sole, I.; Gonzales, C.; Solans, C.; Gutierrez, J. M. Optimization of nano-emulsion prepa- 
ration by low-energy methods at constant temperature using a factorial design study. Colloids Surf., A. 288, 144-150 (2006).

10) Rodriguez-Abreu, C.; Lazzrari, M. Emulsions with structured continuous phases. Cur. Opin. Colloid Interface Sci. 13, 198-205(2008).

11) Weiss, J.; Takhistov, P.; Mcclements, D. J. Functional materials in food nanotechnology. J. Food Sci. 71, 107-116 (2006).

12) Garti, N.; Spernath, A.; Aserin, A.; Lutz, R. Nano-sized self-assemblies of nonionic surfactants as solubilization reservoirs and microreactors for food systems. Soft Matter 1, 206-218(2005).

13) Sanguansri, P.; Augustin, M. A. Nanoscale materials development -a food industry perspective. Trend Food Sci. Technol. 17, 547-556(2006).

14) Yakken Co., Ltd. Jpn. Pat., 3534199, (2004).

15) Márquez, A. L.; Medrano, A.; Panizzolo, L. A.; Wagner, J. R. Effect of calcium salts and surfactant concentration on the stability of water-in-oil (w/o) emulsions prepared with polyglycerol polyricinoleate. J. Colloid Interface Sci. 341, 101-108(2010).

16) Pawlik, A.; Cox, P. W.; Norton, I. T. Food grade duplex emulsions designed and stabilised with different osmotic pressures. J. Colloid Interface Sci. 352, 59-67 (2010).

17) Su, J.; Flanagana, J.; Hemar, Y.; Singh, H. Synergistic effects of polyglycerol ester of polyricinoleic acid and sodium caseinate on the stabilisation of water-oil-water emulsions. Food Hydrocolloids 20, 261-268 (2006).

18) Wilson, R.; Van Schie, B.; Howes, D. Overview of the preparation, Use and biological studies on polyglycerol polyricinoleate (PGPR). Food Chem. Toxicol. 36, 711718 (1998)

19) Hill, R. M.; Li, X.; Washenberger, R. M.; Scriven L. E.; Davis, H. T. Phase behavior and microstructure of water/Trisiloxane $\mathrm{E}_{6}$ and $\mathrm{E}_{10}$ polyoxyethylene surfactant/ silicone oil systems. Langmuir 15, 2278-2289 (1999).

20) Maldonado, A.; Ober, R.; Gulik-Krzywicki, T.; Urbachd, W.; Langevin, D. The sponge phase of a mixed surfactant system. J. Colloid Interface Sci. 308, 485-490 (2007).

21) Miyanoshita, M.; Hashida, C.; Ikeda, S.; Gohtani, S. Development of low-energy methods for preparing food nano-emulsions. J. Oleo Sci. 60, 355-362 (2011) . 